\title{
Hemoglobin A1c as a screening strategy for gestational diabetes
}

\author{
Burke Schaible ${ }^{1}$, Byron C Calhoun ${ }^{2 *}$, Stephen Bush ${ }^{2}$, Beth Ramser $^{2}$, DaraJ Seybold ${ }^{3}$, Mike Broce ${ }^{3}$, Philip Fending ${ }^{3}$, April White ${ }^{3}$, David L Williams $^{2}$ \\ and Luis A Bracero ${ }^{2}$ \\ ${ }^{1}$ Obstetrics and Gynecology Residency, Charleston Area Medical Center, West Virginia, USA \\ ${ }^{2}$ Department of Obstetrics and Gynecology, West Virginia University-Charleston Division, Charleston Area Medical Center, West Virginia, USA \\ ${ }^{3}$ Center for Health Services and Outcomes Research, Charleston Area Medical Center Health Education and Research Institute, West Virginia, USA
}

\begin{abstract}
Introduction: American College of Obstetricians and Gynecologists (ACOG) recommends gestational diabetes mellitus (GDM) testing using a 1-hour 50-gram oral glucose challenge test (24 to 28 weeks gestation) and if elevated $(>140 \mathrm{mg} / \mathrm{dl})$, a 3-hour 100 -gram oral glucose tolerance test.

Objective: To determine if hemoglobin A1c (HbA1c) testing can replace ACOG guidelines, offering a more tolerable, less time-consuming test for GDM.

Methods: This is a prospective cohort study of patients presenting at $\leq 14$ weeks gestation for prenatal care between 11/2011 and 6/2014. HbA1c levels obtained at initial visit and 24 to 28 weeks gestation were compared among patients with and without GDM and tested as a replacement for ACOG guidelines.

Results: Study was comprised of 146 of 364 patients meeting inclusion criteria. Mean age was 25 years, $41.5 \%$ met criteria for obesity, and $50 \%$ had a famly history of diabetes mellitus (DM). The rate of GDM was 8.2\% (12/146.) There was a significant difference in the 24 to 28 week HbA1c test between GDM patients (5.3 $\pm 0.4)$ and non GDM patients $(5.0 \pm 0.3 ; p=0.028)$ Initial HbA1c values at $\leq 14$ weeks were compared to HbA1c at 24 to 28 weeks. Findings revealed a small, but significant decrease in $\mathrm{HbA1c}(5.2 \%$ vs $5.1 \%$, $\mathrm{p}<0.001)$. However, initial mean HbA1c levels were higher in patients with GDM compared to patients without GDM $(5.3 \%$ vs $5.1 \%, \mathrm{p}=0.027)$. Elevated HbA1c ( $25.5 \%)$ and positive testing for GDM showed significant, but weak agreement (Kappa $=0.69, \mathrm{p}=0.041)$, [sensitivity: $25 \%$ and specificity: 92.5\%]. Receiver Operator Curve (ROC) analysis determined optimal threshold of HbA1c of 5.15\% yielding sensitivity of $66.7 \%$; a specificity of $66.4 \%$, PPV of 15.1\%, and NPV of 95.7\%. Analysis of mean change from initial HbA1c $\leq 14$ weeks compared to HbA1c at 24 to 28 weeks resulted in no main effect for GDM, but a significant GDM by HbA1c interaction ( $\mathrm{p}=0.002$ ). GDM patients demonstrated increased mean HbA1c at $\leq 24$ to 28 weeks and non-diabetics decreased mean HbA1c at 24 to 28 weeks gestation.
\end{abstract}

Conclusion: While our data showed that patients with GDM had elevated levels of HbA1c at 24 to 28 weeks gestation, this test is not a reliable replacement for ACOG guidelines with oral glucose challenge testing (OGCT).

\section{Introduction}

Gestational diabetes mellitus (GDM) is a common medical condition that complicates pregnancies. The definition of GDM is not consistent across governing bodies which can make diagnosing GDM challenging. American College of Obstetricians and Gynecologists (ACOG) defines GDM as carbohydrate intolerance that begins during pregnancy [1]. The American Diabetes Association (ADA) defines diabetes as " diabetes mellitus that is first diagnosed in the second or third trimester of pregnancy that is not clearly either preexisting type 1 or type 2 diabetes" [2]. The ADA adopted this definition as a result of the increased prevalence of undiagnosed type 2 diabetes (2). The World Health Organization (WHO) defines GDM as hyperglycemia during pregnancy without prior history of diabetes [3]. The International Association of Diabetes and Pregnancy Study Groups (IADPSG) was the first to recommend that diabetes mellitus (DM) recognized during the first trimester of pregnancy be diagnosed as overt DM rather than as GDM. This is secondary to the increased prevalence of type $2 \mathrm{DM}$ in women of child bearing age. Glucose intolerance in patients with $\mathrm{DM}$ in the first trimester likely precedes pregnancy and therefore is medically managed as pre-gestational [4].

It is estimated that DM complicates over $6 \%$ of pregnancies in the United States. GDM comprises the vast majority of DM in pregnancy compared to the less than $1 \%$ accounted for by pre-existing overt DM [5].

Regardless of the etiology of DM, pregnancy outcomes are worse in pregnant patients with DM, especially with early onset and uncontrolled DM. The Hyperglycemia and Pregnancy Outcomes (HAPO) study which included over 23,000 participants from 9 countries sought to clarify the relationship between increasing levels of maternal hyperglycemia and certain perinatal complications [6]

Treatment of GDM has been shown to reduce the risk of adverse outcomes. Treatment of mild GDM has been shown to reduce the risk of fetal macrosomia, shoulder dystocia, cesarean delivery and hypertensive disorders [7]. One systematic review found sufficient evidence that treatment of all categories of GDM reduced the incidence

${ }^{\star}$ Correspondence to: Byron C Calhoun, 800 Pennsylvania Avenue, Charleston, WV 25302, USA, Tel: 304-388-2819; Fax: 304-388-2915; E-mail: Byron.calhoun@camc.org

Key words: $H b A 1 c$, gestational diabetes, diagnostic testing

Received: August 13, 2018; Accepted: August 24, 2018; Published: August 28, 2018 
of preeclampsia, shoulder dystocia and birth weight greater than 4,000 grams. The review also looked at the possible harms of treatment. The evidence reviewed showed increased prenatal visits for women receiving treatment and one earlier study showed evidence of increased admission to neonatal intensive care units with therapy [8]. Overall however, there was little evidence for adverse effects from treatment in the studies reviewed [8]. ACOG subsequently recommends that all women diagnosed with GDM be counselled on nutrition and exercise at the time of diagnosis of GDM. ACOG and the ADA recommend insulin as first-line medical treatment when nonpharmacologic treatments fail to achieve adequate glycemic control. While there is no absolute threshold to initiate pharmacotherapy, fasting blood sugars greater than $95 \mathrm{mg} / \mathrm{dL}$ and postprandial blood glucose values above $140 \mathrm{mg} /$ $\mathrm{dL}$ at 1 hour or $120 \mathrm{mg} / \mathrm{dL}$ at 2 hours are associated with increased risk of macrosomic infants and serve as a reasonable indication to initiate pharmacotherapy. ACOG acknowledges that there may be clinical cases where oral agents represents an acceptable alternative to insulin for treating GDM [1].

Since treatments have been successful in controlling hyperglycemia in pregnancy, it is important that women be screened and diagnosed appropriately. Additionally, up to one third of those diagnosed with GDM are at an increased risk of developing DM or impaired glucose metabolism as identified at postpartum screening. Fifteen-fifty per cent of women diagnosed with GDM will develop type $2 \mathrm{DM}$ in their lifetime[9]. There is disagreement among major organizations regarding guidelines for screening women for GDM.

IADPSG recommends the use of fasting plasma glucose, Hemoglobin Alc (HbAlc) or random glucose measurement for women at their first prenatal visit to screen for overt DM and GDM. The recommended thresholds for over DM are a fasting plasma glucose greater than or equal to $7.0 \mathrm{mmol} / \mathrm{L}(126 \mathrm{mg} / \mathrm{dL})$, a HbAlc greater than or equal to $6.5 \%$ and or a random glucose greater than or equal to 11.1 $\mathrm{mmol}(200 \mathrm{mg} / \mathrm{dL})$. IADPSG recommends that GDM be diagnosed at the first prenatal visit if the fasting plasma glucose is greater than or equal to $5.1 \mathrm{mmol} / \mathrm{L}(92 \mathrm{mg} / \mathrm{dL})$ and less than $7.0 \mathrm{mmol} / \mathrm{L}(126 \mathrm{mg} /$ $\mathrm{dL}$ ). If the test is negative, IADPSG recommends a 75 grams 2 -hour oral glucose challenge test (OGCT) at 24 to 28 weeks gestation. Overt DM is diagnosed if the fasting plasma glucose is greater than or equal to 7.0 $\mathrm{mmol} / \mathrm{L}(126 \mathrm{mg} / \mathrm{dL})$. GDM is diagnosed if fasting plasma glucose is greater than or equal to $5.1 \mathrm{mmol}(92 \mathrm{mg} / \mathrm{dL}), 1$-hour plasma glucose greater than or equal to $10 \mathrm{mmol}(180 \mathrm{mg} / \mathrm{dL})$, or a 2 hour plasma glucose of $8.5 \mathrm{mmol} / \mathrm{L}(153 \mathrm{mg} / \mathrm{dL})$ [4]. In contrast, ACOG supports the 2 step method for the screening of GDM whereby a screening 1 hour $50 \mathrm{~g}$ OGCT is performed. ACOG states the commonly used plasma glucose cutoffs at 1 hour vary between $130 \mathrm{mg} / \mathrm{dL}-140 \mathrm{mg} /$ $\mathrm{dL}$. If the 1-hour screening OGCT is positive per institutional cutoff, ACOG recommends a 3-hour 100 gram OGCT to confirm the diagnosis of GDM. Plasma glucose is measured fasting prior to the test, 1 hour post consumption, 2 hours post consumption and 3 hours post consumption. ACOG supports two cutoff recommendations: one from the National Diabetes Data Group (NDDG) and Carpenter and Coustan [1]. Due to minimal evidence suggesting one cutoff is more beneficial than the another, ACOG does not recommend one more than the other. Carpenter and Coustan support using the following cutoffs: fasting $\geq 5.3 \mathrm{mmol} / \mathrm{L}$ (95mg/dL), 1 hour $\geq 10 \mathrm{mmol} / \mathrm{L}(180 \mathrm{mg} /$ $\mathrm{dL}), 2$ hour $\geq 8.6 \mathrm{mmol} / \mathrm{L}$ (155 mg/dL), 3 hour $\geq 7.8 \mathrm{mmol} / \mathrm{L}(140 \mathrm{mg} /$ $\mathrm{dL})$. NGGD supports using the following cutoffs: fasting $\geq 5.8 \mathrm{mmol} / \mathrm{L}$ $(105 \mathrm{mg} / \mathrm{dL}), 1$ hour $\geq 10.6 \mathrm{mmol} / \mathrm{L}(190 \mathrm{mg} / \mathrm{dL}), 2$ hour $\geq 9.2 \mathrm{mmol} / \mathrm{L}$ ( $165 \mathrm{mg} / \mathrm{dL}), 3$ hour $\geq 8.0 \mathrm{mmol} / \mathrm{L}$ (145 mg/dL). Two abnormal values are needed during the 3 -hour OGCT to diagnose GDM. There have been some reports that even one abnormal result during the 3-hour OGCT is linked to adverse outcomes but this has not been validated in other studies [1]. The ADA presents both of these guidelines in their recommendations. The ADA does not explicitly recommend one OGCT format over the other [2].

The current glucose screening methods are time consuming, require at least one blood draw, and involve drinking glucose solution known to cause patient dissatisfaction. These difficulties can affect patient satisfaction and deter them from obtaining appropriate screening. A 2004 study suggests that up to $10 \%$ of women at high risk for GDM fail to complete the 3-hour OGTT component of the 2 step test [10].

There are current investigations attempting to find alternative methods for GDM in order to increase testing adherence and minimize patient discomfort. One possible method is measuring a patient's HbAlc in place of OGCTs. Hemaglobin A1c is the measure of glycated hemoglobin which shows the average glucose over the previous three months. As the hemoglobin is exposed to glucose, it becomes progressively more glycated during the 3-month life span of red blood cells. This glycation has a positive correlation with the concentration of glucose in the blood [11]. Hemaglobin Alc measurement does not require fasting, requires only a one-time blood draw, does not require consumption of a concentrated glucose drink and is less time consuming compared to OGCTs. The ADA endorses the use of HbAlc as a diagnostic test for non-gestational DM. The ADA also states that the use of HbAlc may be useful in pregnancy, but may be limited due to increased red blood cell turnover, which would falsely lower the estimated average glucose based on the measured HbA1c [2].

There are several studies which have investigated the relationship between the presence of GDM and HbAlc. There has been conflicting evidence relating to the association of elevated $\mathrm{HbAlc}$ and adverse pregnancy outcomes. Some studies have concluded that patients with elevated $\mathrm{HbAlc}$ measurements are at increased risk of adverse pregnancy outcomes [12-18]. A study from 2014 contradicted this and showed that there was not a significant correlation between HbAlc levels and adverse pregnancy outcomes [19].

Studies using HbAlc as a predictor of GDM during the midsecond trimester show mixed results. Multiple studies have suggested stratification of patients based on $\mathrm{HbAlc}$ does not create adequate sensitivity and specificity for it to replace the OGCTs for diagnosis of all cases of GDM. A 2017 study of Taiwanese women concluded that there was an association between increased $\mathrm{HbAlc}$ and GDM, although it was not significant enough to replace OGCT as a diagnostic approach to GDM [13]. However, some studies have found that HbA1c could be used as a screening test to limit the number of women who need to undergo OGCTs.

Rajput et al. included over 600 women in their study which concluded that an $\mathrm{HbAlc}$ greater than $5.95 \%$ had a specificity of $97.2 \%$ and sensitivity of $28.6 \%$ for diagnosing GDM. Patients with an HbAlc between $5.45 \%$ and $5.95 \%$ required an OGCT while patients with an HbAlc $\leq 5.4 \%$ would be classified as not having GDM without further testing. This model would have correctly identified $85.7 \%$ of cases of GDM while only misclassifying $2.8 \%$ of normal patients as having GDM. This stratification would have prevented the need for an OGCT in $61.8 \%$ of patients [20]. A study completed at First Affiliated Hospital of Sun Yat-sen University by Fong et al., found that women with an HbAlc between $5.7 \%$ and $6.5 \%$ during their first trimester had an adjusted odds ratio of being diagnosed with GDM of 2.4 compared to women who had an HbAlc of less than $5.7 \%$ in the first trimester 
[19]. A New Zealand study concluded that an HbAlc $\geq 5.9 \%$ in early pregnancy was sufficient to diagnose all women with in the study with GDM, while also including a subset of women who would not qualify as having GDM, but still had comparable risks as those with GDM [12].

\section{Purpose}

The purpose of this study was to evaluate the diagnostic screening value of the $\mathrm{HbAlc}$ at 24 to 28 weeks gestation and to determine if it was equivalent or non-inferior to the two step OGCT process of diagnosing GDM that is currently recommended by ACOG.

\section{Materials and methods}

This was a prospective cohort study of obstetric patients from the Women's Medical Center at Women and Children's Hospital in Charleston, West Virginia. All new obstetric patients at the center from November 2011 to June 2014 were informed of the study at their initial prenatal visit. Exclusion criteria included pre-existing $\mathrm{DM}$, a first prenatal care visit beyond 14 weeks gestation, a history of a hemoglobinopathy by hemoglobin electrophoresis, treatment with antiretroviral medication for HIV and the inability to tolerate hyperosmolar glucose as demonstrated by nausea with vomiting after glucose challenge test.

Study Participants received standard prenatal care testing, including a baseline $\mathrm{HbAlc}$ test at their first prenatal care visit $(\leq 14$ weeks gestation) to rule out pre-existing DM and a 1-hour 50-gram OGCT at 24 to 28 weeks. If the patient failed the OGCT per ACOG Guidelines $(\geq 140 \mathrm{mg} / \mathrm{dL})$, they were then given a 3-hour 100-gram OGCT. A second HbAlc was obtained at 24 to 28 weeks gestation. Maternal characteristics of the participating women were collected retrospectively from patient records by review of the electronic medical records.

We estimated that in order to meet a sample size of 75 patients taking the 3-hour 100-gram OGTT, 700 obstetric patients were needed for the initial screening. We estimated that 500 of these initial patients would take the 1-hour 50-gram OGCT at 24 to 28 week due to attrition (e.g., miscarriage, transfer, etc.). Of the 500 patients that completed their 1-hour 50-gram OGTT, we estimated that $18 \%$ might fail the test, leaving us with 90 patients that needed to take the 3 hour OGTT and we estimated that 75 patients would complete 3 hour OGTT testing. Due to prolonged enrollment of patients in the study, we conducted an interim analysis of data and present it.

All analyses were performed using SPSS (IBM Corp. Released 2010. IBM SPSS Statistics for Windows, Version 19.0 Armonk, NY: IBM Corp). Descriptive statistics are expressed in terms of frequencies, percentages, or means plus one standard deviation (SD). Categorical variables were tested by chi-square or Fisher exact tests and continuous variables were tested by student $\mathrm{t}$-test when deemed appropriate. A ' $\mathrm{p}$ ' value of 0.05 or less was considered significant.

\section{Results}

One hundred forty-six of 364 patients meeting inclusion criteria were included in the study and 40 completed the 3 hour OGTT .The mean age of included participants was 25 years. The rate of obesity was $41.5 \%$. Fifty per cent of individuals included had a famiy history significant for DM. The rate of GDM was $8.2 \%(12 / 146$.) There was a significant difference in the 24 to 28 week $\mathrm{HbAlc}$ test between GDM patients $(5.3 \pm 0.4)$ and non GDM patients $(5.0 \pm 0.3 ; \mathrm{p}=0.028)$ Initial $\mathrm{HbA} 1 \mathrm{c}$ values compared to 24 to 28 weeks revealed a small but significant decrease (5.2 vs 5.1, $\mathrm{p}<0.001$ ). However, mean HbA1c levels were shown to be higher in patients with GDM (5.3 vs 5.1, p=0.027). Elevated HbAlc (>5.5) and positive GDM showed significant, but weak agreement (Kappa $=0.69, \mathrm{p}=0.041$ ), [sensitivity: $25 \%$ and specificity: 92.5\%]. ROC curve analysis determined optimal threshold 5.15 yielding sensitivity: $66.7 \%$; specificity: $66.4 \%$. Analysis of mean change from initial $\mathrm{HbAlc}$ to $\mathrm{HbAlc}$ at 24 to 28 weeks resulted in no main effect for GDM, but a significant risk of GDM by HbAlc interaction (See Figure 1; $\mathrm{p}=0.002$ ), GDM patients demonstrated increased mean $\mathrm{HbAlc}$ at $\leq 24$ to 28 weeks and non-diabetics decreased mean HbAlc at 24 to 28 weeks gestation.

\section{Discussion}

Our data showed that patients with GDM had elevated levels of HbAlc at 24 to 28 weeks gestation, but that this test is not a reliable replacement for ACOG guidelines. The most interesting finding of the study was the level of HbA1C that correlated to GDM (5.3\%) compared to patients without GDMA (5.1\%). This was in spite of the relatively small decreased in $\mathrm{HbA1C}$ from $<14$ weeks to 24 to 28 weeks (5.2 vs 5.1, $\mathrm{p}<0.001$ ) which could be related to the dilutional effects of pregnancy with more rapid turn over of red cells [2]. These findings would challenge the IADPSG findings of a HbAlc greater than or equal to $6.5 \%$ beingconsistent with pre-existing DM in pregnancy but demonstrate rather, that, a much

Many factors contribute to insulin resistance during pregnancy which increase onsiderably during the third trimester. Most of these factors are hormones produced by the placenta which increase with the growing placental mass to include: cortisol, human placental lactogen, progesterone and estrogen [21]. Given this trend, a longitudinal assessment of a HA1c over the previous 3 months will not adequately reflect the level of insulin resistance at the time of a one hour oral glucose challenge test. Furthermore the HA1c merely assesses the average glucose level while the oral glucose challenge test assesses the immediate response to a glucose load. On the molecular level, some research suggests that phosphorylation of tyrosine kinase receptors mediates downstream effects of the insulin receptors substraight- 1 (IRS-1); and this effect may be more prominent in the third trimester.

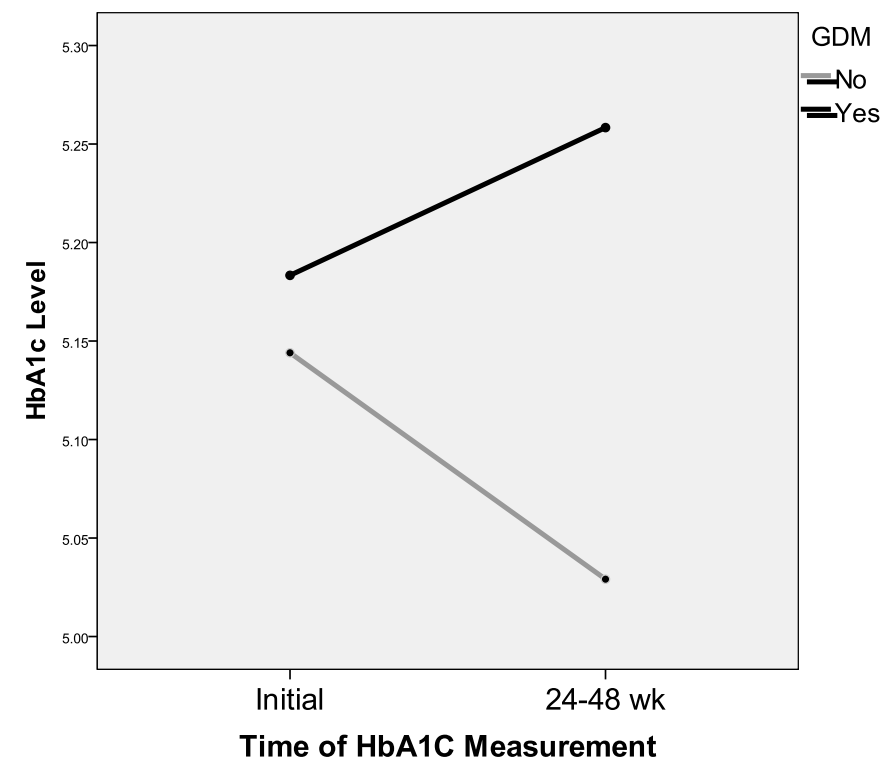

Figure 1. Mean HbA1C level by GDM 
Tumor necrosis factor alpha levels also change significantly in the third trimester and have an inverse relationship to insulin sensitivity [22]. This may further contribute to insulin resistance. Overall the aforementioned changes in pregnancy during the third trimester provide a physiologic explanation for the importance of waiting until the $24^{\text {th }}$ or $28^{\text {th }}$ week in pregnancy to assess insulin resistance.

Lower threshold of $5.3 \%$ might be more appropriate in screening and diagnosing GDM.

Strengths of the study its prospective nature, the serial evaluation of patients with each patient serving as their own control, and single laboratory (no laboratory variance).

The major limitation to our study includes not enrolling the required 75 patients into th study with too small a number of patients to definitively recommend $\mathrm{HbAlC}$ as a screening tool for GDMA. Conversely, the study does raise the significant question of the entry level of $\mathrm{HbA1C}$ necessary to trigger early and/or enhanced screening for DM in pregnancy. Also, co-morbidities in our population might also have obscured our findings since $49 \%$ (72/146 of our patients also had factors known to increase the incidence of GDMA (i.e obesity, hypertension, PCOS).

Further prospective studies are needed to validate what threshold of $\mathrm{HbA1C}$ should be used to cause earlier and enhanced screening as our study did not demonstrate $\mathrm{HbA1C}$ could be a replacement for the present ACOG glucose tolerance testing-screening guidelines.

\section{References}

1. Gestational Diabetes Mellitus - ACOG [Internet]. Available from: https://www.acog.org Clinical\%20Guidance\%20and\%20Publications/Practice\%20Bulletins/Committee $\% 20$ on $\% 20$ Practice $\% 20$ Bulletins $\% 20$ Obstetrics/Gestational\%20Diabetes\%20Mellitus. aspx Accessed Date: 11 Feb 2018.

2. American Diabetes Association (2018) 2. Classification and Diagnosis of Diabetes: Standards of Medical Care in Diabetes - 2018. Diabetes Care 41(Supplement 1): S1327. [Crossref]

3. WHO $\mid$ About diabetes [Internet]. Available from: http://www.who.int/diabetes/action online/basics/en/index 1.html Accessed Date: 18 Feb 2018

4. Duran A, Sáenz S, Torrejón MJ, Bordiú E, Valle L del, et al. (2014) Introduction of IADPSG criteria for the screening and diagnosis of gestational diabetes mellitus results in improved pregnancy outcomes at a lower cost in a large cohort of pregnant women: the St. Carlos Gestational Diabetes Study. Diabetes Care 37: 2442-2450. [Crossref]

5. Correa A, Bardenheier B, Elixhauser A, Geiss LS, Gregg E (2015) Trends in prevalence of diabetes among delivery hospitalizations, United States, 1993-2009. Matern Child Health J 19: 635-642. [Crossref]

6. HAPO Study Cooperative Research Group1, Metzger BE, Lowe LP, Dyer AR, Trimble ER, et al. (2008) Hyperglycemia and Adverse Pregnancy Outcomes. N Engl J Med 358: 1991-2002. [Crossref]
7. Landon MB, Spong CY, Thom E, Carpenter MW, Ramin SM, et al. (2009) A multicenter, randomized trial of treatment for mild gestational diabetes. $N$ Engl J Med 361: 1339-1348. [Crossref]

8. Hartling L, Dryden DM, Guthrie A, Muise M, Vandermeer B, et al. (2013) Benefits and harms of treating gestational diabetes mellitus: a systematic review and meta-analysis for the U.S. Preventive Services Task Force and the National Institutes of Health Office of Medical Applications of Research. Ann Intern Med 159: 123. [Crossref]

9. Preventing type 2 diabetes: public health implications for women with a history of gestational diabetes mellitus- ClinicalKey [Internet]. Available from: https:// www-clinicalkey-com.www.libproxy.wvu.edu/\#!/content/playContent/1-s2.0S000293780800642X. Accessed Date: 11 Feb 2018.

10. Agarwal MM, Punnose J, Dhatt GS (2004) Gestational diabetes: problems associated with the oral glucose tolerance test. Diabetes Res Clin Pract 63: 73-74.

11. David McCulloch. Estimation of blood glucose control in diabetes mellitus - UpToDate [Internet]. UpToDate.com.Available from: https://www.uptodate.com/contents/ estimation-of-blood-glucose-control-in-diabetes-mellitus?source=history_widget Accessesd Date: 18 Feb 2018.

12. Hughes RCE, Moore MP, Gullam JE, Mohamed K, Rowan J (2014) An early pregnancy $\mathrm{HbAlc} \geq 5.9 \%(41 \mathrm{mmol} / \mathrm{mol})$ is optimal for detecting diabetes and identifies women at increased risk of adverse pregnancy outcomes. Diabetes Care 37: 2953-2959. [Crossref]

13. Ho YR, Wang P, Lu MC, Tseng ST, Yang CP, et al. Associations of mid-pregnancy $\mathrm{HbAlc}$ with gestational diabetes and risk of adverse pregnancy outcomes in high-risk Taiwanese women. PLoS One 12: e0177563. [Crossref]

14. Sweeting AN, Ross GP, Hyett J, Molyneaux L, Tan K, et al. (2017) Baseline HbA1c to identify high-risk gestational diabetes: utility in early vs standard gestational diabetes. $J$ Clin Endocrinol Metab 102: 150-156. [Crossref]

15. Soumya S, Rohilla M, Chopra S, Dutta S, Bhansali A, et al. (2015) HbAlc: A useful screening test for gestational diabetes mellitus. Diabetes Technol Ther 17: 899-904. [Crossref]

16. Mañé L, Roux FL, Antonia J, Benaiges D, Rodríguez M, et al. Role of first-trimester hba1c as a predictor of adverse obstetric outcomes in a multiethnic cohort. $J$ Clin Endocrinol Metab 102: 390-397. [Crossref]

17. Hammouda SAI, Hakeem R (2015) Role of HbA1c in predicting risk for congenita malformations. Prim Care Diabetes 9: 458-464. [Crossref]

18. Ye M, Liu Y, Cao X, Yao F, Liu B, et al. (2016) The utility of HbAlc for screening gestational diabetes mellitus and its relationship with adverse pregnancy outcomes. Diabetes Res Clin Pract 114: 43-49. [Crossref]

19. Fong A, Serra AE, Gabby L, Wing DA, Berkowitz KM (2014) Use of hemoglobin A1c as an early predictor of gestational diabetes mellitus. Am J Obstet Gynecol 211: 641. e1-641.e7. [Crossref]

20. Rajput R, Yadav Y, Rajput M, Nanda S (2012) Utility of HbA1c for diagnosis of gestational diabetes mellitus. Diabetes Res Clin Pract 98: 104-107. [Crossref]

21. Nadal A, Alonso-Magdalena P, Soriano S, Ropero AB, Quesada I (2009) The role of oestrogens in the adaptation of islets to insulin resistance. J Physiol 587: 5031-5037. [Crossref]

22. Resnik R, Lockwood C, Moore T, Greene M (2009) Creasy and Resnik's maternal-fetal medicine :principles and practice. Saunders/Elsevier, Philadelphia, USA

Copyright: (C2018 Schaible B. This is an open-access article distributed under the terms of the Creative Commons Attribution License, which permits unrestricted use, distribution, and reproduction in any medium, provided the original author and source are credited. 